(C) 2017 IEEE. Personal use of this material is permitted. Permission from IEEE must be obtained for all other uses, in any current or future media, including reprinting/republishing this material for advertising or promotional purposes, creating new collective works, for resale or redistribution to servers or lists, or reuse of any copyrighted component of this work in other works. 


\title{
Flipped Gaming for Enhanced Learning Outcome Crisis Preparedness Courses
}

\author{
Geir Ove Venemyr, Bjørn T. Bakken, Linda Kiønig, Ole Jørgen S. Ranglund, Stig Holen, Hanne Haave, \\ Tone Vold, Robin Braun
}

\begin{abstract}
Preparing for crisis and incidents have gained an increased focus, also within the educational system. At The Inland University of Applied Sciences, Campus Rena, in Norway, a Bachelor study is developed to cater for the increased need for educating staff not only in municipalities, but also in private organizations. Regulations and governmental instructions have also created a void between staff that can and know how to handle crisis and staff that need to know how to handle crisis. In addition, the preparedness issue, in order to avoid crisis, has received a lot of attention. The study has until recently been a mix of ordinary classroom education and exercises, both live and table top exercises, both which is costly and time consuming both in planning and execution. Two years ago, some faculty staff and a small group of students started to look into using games for educational purposes. Some of the games were free ware and downloadable from the internet, another game was developed by Bohemia Interactive Simulations (https://bisimulations.com/). Combining using MeTracker (http://www.concorde-
\end{abstract} project.eu/index.php/results/developments/the-training-tools/1metracker) for organizing the work during a training process, and the developed game, this has proved to be a powerful tool for learning about how to be prepared for and handle crisis. Even if the initial costs for development and licenses have been somewhat substantial, the tools will provide the students with a unique possibility of simulating crisis in a higher volume than what is possible using live exercises. So far, the faculty staff has developed the scenarios for the students to play. The change from this is now to use a game based environment to play scenarios developed by the students themselves. The students that have tested this is in the third year of their study and the preliminary feedback from the students on this approach has been positive. The paper presents the results from interviews and observations, looking to establish how this approach has supported an enhanced learning outcome. Preliminary results provide support to the ideas of using the students own backgrounds and starting the reflection processes earlier (than in "ordinary" exercises). Also letting the students be actors in their own scenario can contribute towards the learning outcome. This combination of utilizing a game based and computer-based environment, with a physical play sphere, in combination with a prior session with scenario development, can prove to be the next step in utilizing game based learning. The paper also present a theoretical reasoning for utilizing games, and discuss how developing scenarios support reflection processes that will in turn enhance learning outcomes from a course. Kolb's experiential learning cycle in its original form provide valuable clues towards the processes that needs to be considered, and Donald Schön's works regarding the "reflective practitioner" contributes to enhance the understanding of how the learning process and how we as faculty staff can support

Geir Ove Venemyr, Bjørn T. Bakken, Linda Kiønig, Ole Jørgen S. Ranglund, Stig Holen, Hanne Haave, Svein Bergum and Tone Vold are all with The Inland University of Applied Sciences, Norway

Robin Braun is with the School of Electrical and Data Engineering, University of Technology Sydney, Australia our students in becoming reflective practitioners that are better equipped to prevent and handle crisis.

Index Terms-crisis management and prevention, reflection processes, reflective practitioners, co-creating scenarios, playing for learning, serious gaming

\section{INTRODUCTION}

O ERIOUS games, or games for learning, has been around for a while (Bergeron 2006, Michael and Chen 2006, Valverde 1973). Still the same applies today as for several decades ago; using games are cheaper, safer and allows for a more varied training[20]. It is, however, necessary to adapt the game to the different curricula. At the Inland Norway University of Applied Sciences, Rena, Norway, we offer a study program within, Crisis Management, Crisis Communication and Crisis Prevention. The target audience is everyone within rescue and call out services, employees in municipalities and employees in organizations in general. The Norwegian Directorate for Civil Prodection[14], has issued an order that states that all municipalities are to have crisis preparedness plan and train for possible crisis[14]. This implies the need of educational initiatives that cater for these issues. There are several educational options for specified educations such as for fire fighters, police, etc. However, the multidisciplinary option which allows the different people involved in a possible incident in e.g. a municipality, to work together, is what we wanted to develop. Theory on crisis, crisis management, crisis communication and crisis prevention can be taught, but the understanding of the cooperative efforts needed also need a more "hands on" approach. This means to train in exercises. However, live exercises are expensive, time consuming and the learning outcomes from such a learning activity compared to the efforts that is spent from both the educational staff and the learners (students) are great, but it is still not possible to organize such exercises for many learning purposes. Hence, the introduction of using games and simulations. The game, based on the platform from Bohemia Interaction Simulations[1], that also have produced the game Steel Beasts, used in some educations that involve using military vehicles[24]. The study program is a three-year program (Bachelor degree) that includes Crisis Management, Crisis Communication and Crisis Prevention. It has emerged from separate courses into a Bachelor Degree due to the increasing demand from the public sector and from the legislation presented by e.g. the Norwegian Directorate of Civil Defence (DSB). Since most of the students 
are in a work life, working with issues within planning crisis prevention, it is of great importance to support the learning processes that optimizes the learning outcome from the study program and that they are able to utilize the learning outcome back in their organizations. In other words, we need them to become "reflective practitioners" as described by Donald Schön[18, 19]. This implies using methods for reflective learning within the educational program. In this paper we have combined our awareness of how adults learn with utilizing reflections for learning purposes. It is possible to "kick start" the learning process by involving and including the students into the development of scenarios for the gaming sessions. We wanted to test out how acknowledging the competencies of the adult students and using their knowledge to develop scenarios would support their learning process. In the paper we present the theory that has enlighten our study, how we went about collecting the data, and our findings and results from our investigations. Lastly, we present a preliminary conclusion and the further planned research to be undertaken.

\section{THEORETICAL BACKDROP}

Here we present the theory we have relied on embarking on our research project of inviting our students to contribute and co-develop scenarios for playing in class. Students at the university are adults and have thus a different motivation (than children) to learn. Instead of it being "because the teacher (or role model) says so", it is now more about "how is this useful for me or my job situation"[12]. Investigations show that a lot of investments are made in external courses to educate adults in organizations[9, 8]. However, the same investigations show that the workers learn most in their workplace as they are then learning about how to execute a job or a task[8]. Deducted from these studies are that the learning in the organizations are perceived as relevant to the execution of their work and the learning in the courses offered a more abstract approach that did not provide the immediate usage of the learning outcome. Combining the two; both offering the "abstract" learning AND the "hands on" -aspect, then require that the students are able to present what is relevant for them. Utilizing the students' own backgrounds is what John Dewey advocated in order to support the learning process[6, 7]. Dewey also contributed towards issues of learning by experiencing or experiential learning. David A. Kolb[13] presented "the experiential learning cycle" where he explains the combination of experience with reflection processes and it importance towards enhancing the learning outcome. Reflecting upon experiences and looking at ways of improving an action implies the processes that Donald Schön refers to as "reflection on action" and "reflection in action on action"'[19, 18]. As Kolb's experiential learning cycle implies, it is also important to reflect before undertaking a new action. This resembles what John Cowan calls "reflection before action"[2]. To reflect before an action can be facilitated as a workshop where the teacher facilitates the process of making the students bring their experiences or work life interests forward. The workshop should end up with having created scenarios that can be put to action. In this way, the students will be encouraged to start the reflection processes earlier than they would have if the teachers made the scenario. The idea of having the students making the scenarios is partially inspired by the experiences from using an extended version of the "flipped classroom" $[23,22,24,25,21]$. In some of the courses in the study program "Knowledge Management" at The Inland Norway University, the students have been contributing towards co-creating assignments to solve in order to learn the theory and its application back in their work life.

\section{THE PROJECT}

Students at the study program of Crisis Management and Crisis Preparedness tested the newly purchased game platform with a scenario prepared by a game master. This scenario was pre-developed. The students (approximately 13-14 students) were divided into two groups. Each group was to make a scenario for others to play. They ended up playing eachothers scenario. One scenario was about a fire in a multi-storey building, the other was about a landslide. The game master who programmed the two different scenarios also developed the graphics for the two co-generated scenarios. Each group then worked as the play staff for the other group. The cogeneration of scenarios were also to serve as reflection process prior to the action. During the game play, there were pauses where the lecturers facilitated reflection processes (reflection in action on action). After the game play there was a debrief, and an after action review[26] (reflection on action).

\section{Methodological APPROACH}

For this paper the data are from interviews and observations[3, $5,16,17]$. The data are collected in the sessions with the students. The group interviews have been coordinated with debriefing/reflection sessions. The observations are notes from the teachers during the different stages of the project. Analysing the data has been done collaboratively, discussing the different teachers and researchers notes and observations from the different session. We have looked at the data with the "glasses" of all being researchers and educators. This means that the aim of the study - providing adapted and useful learning and training to adult learners - has been the focal point. It has been important to evaluate how the approaches to support adult learning processes have had an impact on the learning outcome. Our immediate understandings have been presented to the students during the sessions, which can be compared to "member checking"[10].

\section{RESULTS AND DISCUSSION}

Knowing that adults learn by being included, involved and activated, the positive feedback did not come as a total surprise. The negative feedback was on less optimal functioning hardware (common communication platform that represented an abnormal situation for the students that came from call out services). They responded positively on the work of coproducing the scenarios. They needed some explanations in order to be enabled and empowered to contribute, but when 
they understood the concept and the reasoning, they were serious co-creators and both of the scenarios turned out to be playable and to offer learning opportunities. This is coherent with the experiences from "flipped classroom"[21]. When encouraged, enabled and empowered to share their knowledge, experiences and work interests, they are valuable contributors. They also claim this to be a learning opportunity as they learned more about each other and each other's backgrounds, as they had to share experiences and work interests. Forming the experiences and work interests into ideas for scenarios also presented an opportunity for reflection. They needed to look at different options as to the outcome of playing the scenario and discuss the playability of the scenarios. Some of the students work in call out services and they have been taking part in emergency exercises, sometimes involving several of the different call out services (ambulance, police, etc.). Sharing their experiences also provide their fellow students with exercise on how to construct playable scenarios. It requires, however, facilitation skills by the teacher to organize such a process. During the gaming sessions, the students were actors in their own developed scenario, whilst the other group were playing. A couple of times the teacher/facilitator had to pause the gaming in order to facilitate a reflection process. This process is similar to what Schön calls "reflection in action on action" $[19,18]$. The facilitator need to be vigilant when utilizing this type of reflection as it is of major importance not to break flow[4]. Breaking flow may distort the learning process[11]. The teachers in this case were extremely cautious and skilled, and were able to conduct a "reflection in action on action"[18]. The students claim that the break and discussions (their descriptions) were useful - for both groups. The group "owning" the scenario learned about functionality of their scenario, and the students playing the scenario learned about different approaches to handling the cases and discussed different solutions. This they claim contributed towards their learning process. The process of debriefing afterwards is also important. However, the students seem rather tired after such a gaming session. They seem to be easily distracted and although they claim this reflection (on action) to be useful and contributing to their learning outcome, we felt they were more eager to go home. Ideally it would be interesting to have had a second opportunity of reflection; reflection on action -longer after action[22]. To be able to "digest" the learning, and maybe even write learning journals[15] and then have a second reflection process. This reflection process could also be used to develop the scenarios further and improve them, and maybe play with different parameters in order to enlighten different aspects of these particular situations. This would be in alignment to Kolb's experiential learning cycle[13].

\section{CONCLUSIONS}

The students claim the reflection processes, and the gaming, to have contributed towards an enhanced learning process. A part from some poorly functioning communication tool that somewhat also broke flow[4], the whole experience was interesting and positive and they would like to do it again utilizing other situations they would like to train on. The reflection processes, once being enabled and empowered to contribute towards co-creating the scenarios, worked as planned and contributed towards the enhanced learning outcome. Ideally a second reflection process - a "longer after action review"[22] should be utilized to further enhance the learning outcome from the gaming session. This would also contribute towards improving the scenarios and develop different options for learning from the same scenario. It is important to ensure that all hardware work as expected. Interruptions that are interpreted as a breaking of flow may cause a reduced learning experience[11].

\section{FURTHER RESEARCH}

We need to test this on a larger number of students. Also it would be interesting to investigate if the students are able to utilize their knowledge gained from the gaming sessions back in their organizations. The positive feedback has contributed towards planning new sessions this autumn. In addition to observations, interviews and group interviews we will also send the students a survey so that they are able to reflect and give feedback separate from each other. We also consider utilizing learning journals that the students can hand in for us to use as research data.

\section{REFERENCES}

[1] BohemiaInteractiveSimulations. Bohemiainteractivesimulations, 2016.

[2] John Cowan. On becoming an innovative university teacher: reflection in action. Society for Research into Higher education \& Open University Press, Buckingham, 2006.

[3] John W. Creswell. Research Design: Qualitative, Quantitative, and Mixed Methods Approaches. Sage Publications, Inc, Thousand Oaks, 2nd edition, 2003.

[4] Mihaly Csikszentmihalyi. Flow: The Pshychology of Optimal Experience. Harper \& Row, New York, 1990.

[5] Norman K. Denzin and Yvonna S. Lincoln. The Sage handbook of qualitative research. Sage, Thousand Oaks, Calif., 2005.

[6] John Dewey. Experience \& Education. Touchstone, New York, 1938.

[7] John Dewey. Democracy and Education. Barnes \& Noble Books, 2005.

[8] Cathrine Filstad. Organisasjonslaring : - fra kunnskap til kompetanse. Vigmostad \& Bjørke, Bergen, 2. utg. edition, 2016.

[9] Cathrine Filstad and Gunnhild Blåka. Learning in organizations. Cappelen, Oslo, 2007.

[10] Egon G. Guba and Yvonna S. Lincoln. Fourth generation evaluation. Sage, Newbury Park, Calif., 1989.

[11] David Kember, Alice Jones, Alice Loke, Jan McKay, Kit Sinclair, Harrison Tse, Celia Webb, Frances Wong, Marian Wong, and Ella Yeung. Determining the level of reflective thinking from students' written journals using a coding scheme based on the work of mezirow. 
International Journal of Lifelong Education, 18(1):1830, 1999.

[12] Malcolm S. Knowles. The adult learner: a neglected species. Gulf Pub. Co, Houston, 1990.

[13] David A. Kolb. Experiential learning: experience as the source of learning and development. Prentice-Hall, Englewood Cliffs, N.J., 1984.

[14] Direktorate Members. Veiledning til forskrift om kommunal beredskapsplikt, 2012.

[15] Jennifer A. Moon. Learning journals: a handbook for reflective practice and professional development. Routledge, London, 2006.

[16] Laura O'Dwyer and James A. Bernauer. Quantitative Research for the Qualitative Researcher. SAGE Publications, Thousand Oaks, 2013.

[17] Michael Quinn Patton. Qualitative research \& evaluation methods. 2002.

[18] Donald A. Schön. Educating the reflective practitioner. Jossey-Bass, San Francisco, Calif., 1987.

[19] Donald A. Schön. The reflective practitioner : how professionals think in action. Aldershot: Avesbury, 1991.

[20] Horace H. Valverde. A review of flight simulator transfer of training studies. Human Factors, 15(6):510-522, 1973.

[21] Aud Tone Vold, Linda Vibeke Kiønig, and Ole Jørgen Stefferud Ranglund. Students as content producers: How activating students can enrich an online course. In International Conference of E-Learning, pages 230-237. Academic Conferences LTD.

[22] $\mathrm{T}$ Vold. Being ready for emergencies- innovative approaces to fostering learning in and between organizations. In Society for Desing Sience and Process, editors, SDPS. SDPS.

[23] T Vold. How can the concept of flipped classroom support the development of reflective practitioners in higher education? In ITHET2014. University of York, UK.

[24] Tone Vold and Simon McCallum. Report for the norwegian army military academy: Use of game based technology at nama - a study using steelbeasts professional. Report, Hedmark University College, 2009.

[25] Tone Vold, Sule Yildirim-Yayilgan, and Jan Sørnes. New takes on learning in organizations when using role play simulation, 2014.

[26] D von der Oelsnitz and Michael W. Busch. Teamlernen durch after action review. Personalführung, (2):54-62, 2006. 